\title{
Paolo Tamassia, Sartre e il Novecento
}

\section{Michela Gardini}

\section{(2) OpenEdition}

\section{Journals}

\section{Edizione digitale}

URL: http://journals.openedition.org/studifrancesi/6091

DOI: 10.4000/studifrancesi.6091

ISSN: 2421-5856

\section{Editore}

Rosenberg \& Sellier

\section{Edizione cartacea}

Data di pubblicazione: 1 mai 2011

Paginazione: 211-212

ISSN: 0039-2944

\section{Notizia bibliografica digitale}

Michela Gardini, «Paolo Tamassia, Sartre e il Novecento», Studi Francesi [Online], 163 (LV | I) | 2011,

online dal 30 novembre 2015, consultato il 13 janvier 2021. URL: http://journals.openedition.org/ studifrancesi/6091 ; DOI: https://doi.org/10.4000/studifrancesi.6091

\section{Questo documento è stato generato automaticamente il 13 janvier 2021.}

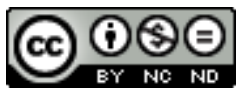

Studi Francesi è distribuita con Licenza Creative Commons Attribuzione - Non commerciale - Non opere derivate 4.0 Internazionale. 


\title{
Paolo Tamassia, Sartre e il Novecento
}

\author{
Michela Gardini
}

\section{NOTIZIA}

PAOLO TAMASSIA, Sartre e il Novecento, Trento, Dipartimento di Studi Letterari, Linguistici e Filologici dell'Università degli Studi di Trento, 2009, pp. 161.

1 Il saggio di Paolo Tamassia Sartre e il Novecento si presenta come una ricca e approfondita ricognizione dei rapporti che l'opera di Sartre intrattiene con il pensiero dei maggiori intellettuali del Novecento, da Bataille a Foucault, da Nancy a Spanos e a Lyotard fra gli altri.

2 L'A. dimostra quanto la speculazione sartriana, lungi dall'essere ingabbiata unicamente nella teoria dell'engagement, sia in realtà poliedrica e sempre in fieri, aperta al confronto con le sollecitazioni di natura letteraria, estetica, filosofica e politica che hanno attraversato il xx secolo. Nella prima parte del saggio (Dialoghi I. Bataille, Foucault, Nancy) viene dapprima messo in evidenza quanto la distanza di Sartre rispetto alla concezione batailliana della letteratura intesa come dépense, passione avente per oggetto null'altro che se stessa, vada in realtà ridimensionata, sulla base della revisione alla quale lo stesso Sartre sottopose progressivamente la teoria dell'engagement, criticando sia la strumentalità della scrittura letteraria che l'asservimento dell'arte a fini ad essa estranei. Secondariamente, Tamassia procede ad un confronto tra Sartre e Foucault sulla base del concetto di trasgressione, che funge dunque da comun denominatore tra $\mathrm{i}$ due pensatori, ma mentre per Foucault la parola letteraria è sovversiva di per sé e in questo risiede inoltre la sua prossimità con la follia, per Sartre la trasgressione si dà nella referenzialità della prosa letteraria, la quale rimanda sempre ad un oggetto fuori di sé. Infine, il rapporto tra Sartre e Nancy, di natura prettamente estetica, è invece incentrato sul concetto di arte come "vestigio", partendo da una concezione dell'arte non più come rappresentazione dell'idea né tanto meno imitazione di un modello, bensì come traccia compiuta in sé, pura presenza che non presuppone alcun paradigma figurativo. 
3 Nella seconda parte (Dialoghi II. Sartre e il postmoderno) l'A. sottolinea come le preoccupazioni estetiche siano al centro dell'interlocuzione con la riflessione postmoderna, il che emerge da testi quali Le Peintre sans privilèges, scritto in occasione di un'esposizione delle opere di Lapoujade, e Sculptures a $n$ dimensions, dedicato all'opera dello scultore David Hare. In entrambi questi testi, in sintonia con il pensiero di Lyotard, Sartre ribadisce il concetto di arte come creazione di un oggetto nuovo, sottratto a qualsiasi mimetismo. Tamassia argomenta altresì come sia l'autobiografia Les Mots sia i due testi scritti all'indomani della morte dell'amico Merleau-Ponty, e anche il saggio Je-Tu - Il dedicato al romanzo L'Inachevé di Manuel Puig presentino significativi punti di contatto con la riflessione postmoderna di Spanos, in particolare a partire dal concetto di temporalità aperta, in cui il passato non viene dato come un'esperienza rappresentabile in sé, bensì sempre in presa diretta col presente.

4 Nella terza ed ultima parte (Dialoghi III. L'antico nel Novecento) l'attenzione dell'A. si focalizza sulla rilettura politica che Sartre fece delle Troiane di Euripide all'epoca della guerra di Algeria. Se già di per sé il mito trascende i confini temporali rivelando sempre la propria attualità, secondo Sartre già nelle intenzioni di Euripide la pièce era una palese condanna della guerra e dell'espansionismo coloniale. Infine, sempre nella prospettiva della rivisitazione dell'antico funzionalmente all'interpretazione del presente, nell'ultimo capitolo Tamassia prende in esame il testo (postumo e incompiuto) che Sartre iniziò a scrivere prima di annunciare il proprio addio alla letteratura, La Reine Albemarle ou le Dernier Touriste, il quale si configura come un originale omaggio all'Italia.

5 Completa il saggio un'esaustiva e articolata bibliografia che testimonia del fervido dibattito critico intorno ad uno degli intellettuali in assoluto più rappresentativi del Novecento. 